\title{
RACISMO, RELIGIÃO E EDUCAÇÃO NO BRASIL: DESAFIOS CONTEMPORÂNEOS
}

\author{
Carolina Rocha Silva ${ }^{1}$
}

\begin{abstract}
Resumo: Raça Negra e Educação 30 anos depois: E agora do que mais precisamos falar? Minha história é reflexo desses 30 anos de lutas históricas do Movimento Negro, dos avanços em termos de direitos para população negra e dos tantos desafios que temos. Os professores da educação básica sentem dificuldade de implementar a lei 10.639, que se refere à inclusão do ensino de História da África, das questões raciais e da cultura afro-brasileira, amplamente demonizada, na grade curricular. Pensando em mudanças resolvi criar oficinas itinerantes nas escolas para abordar todo processo histórico de apagamento e demonização das religiões afro-brasileiras na história do Brasil. Contribuindo, assim, para uma educação na qual o racismo e todas as formas de opressão sejam descontruídos na luta por igualdade.
\end{abstract}

Palavras chave: Racismo; Religião; Educação.

\section{RACISM, RELIGION AND EDUCATION IN BRAZIL: CONTEMPORARY CHALLENGES}

\begin{abstract}
Black Race and Education 30 years later: Now what else do we need to talk about? My story is a reflection of these 30 years of historical struggles of the Black Movement, the advances in terms of rights for black population and the many challenges that we have. Basic education teachers find it difficult to implement law 10.639, which refers to the inclusion of the teaching of African History, racial issues and Afro-Brazilian culture, widely demonized, in the curriculum. Thinking of changes, I decided to create itinerant workshops in schools to address all historical processes of erasure and demonization of Afro-Brazilian religions in the history of Brazil. Thus contributing to an education in which racism and all forms of oppression are deconstructed in the struggle for equality.
\end{abstract}

Keywords: Racism; Religion; Education.

\section{RACISME, RELIGION ET EDUCATION AU BRESIL: DEFIS CONTEMPORAINS}

Résumé: Race noire et éducation 30 ans plus tard: De quoi d'autre devons-nous parler? Mon histoire est le reflet de ces 30 années de luttes historiques du Mouvement noir, des avancées en termes de droits pour la population noire et des nombreux défis qui nous attendent. Les enseignants en éducation de base ont du mal à appliquer la loi 10.639, qui mentionne l'inclusion de l'enseignement de l'histoire africaine, des questions raciales et de la culture afro-brésilienne, largement diabolisée, dans les programmes. En pensant aux changements, j'ai décidé de créer des ateliers itinérants dans les écoles pour aborder tous les processus historiques d'effacement et de diabolisation des religions afro-brésiliennes dans l'histoire du Brésil. Contribuant ainsi à une éducation dans laquelle le racisme et toutes les formes d'oppression sont déconstruits dans la lutte pour l'égalité.

\footnotetext{
${ }^{1}$ Carolina Rocha Silva é mulher negra, escritora, militante feminista e professora. Mestre em história pela UFF e doutoranda em Sociologia no IESP/UERJ. É pesquisadora da Coordenadoria de Experiências religiosas africanas e afro-brasileiras, racismo e intolerância religiosa, vinculada ao Laboratório de História das Experiências Religiosas (LHER-UFRJ). Autora do livro: "O Sabá do Sertão: feiticeiras, demônios e jesuítas no Piauí Colonial", Paco Editorial, 2015. Membro da Associação Brasileira de História das Religiões (ABHR) e do Congresso Brasileiro de Pesquisadores Negros (Copene). E-mail: carolinarocha18@gmail.com.
} 
Mots-clés: Racisme; La Religion; L'éducation.

\section{RACISMO, RELIGIÓN Y EDUCACIÓN EN BRASIL: DESAFÍOS CONTEMPORÁNEOS}

Resumen: Raza Negra y Educación 30 años después: ¿Y ahora qué más necesitamos hablar? Mi historia es reflejo de estos 30 años de luchas históricas del Movimiento Negro, de los avances en términos de derechos para la población negra y de los tantos desafíos que tenemos. Los profesores de la educación básica sienten dificultad para implementar la ley 10.639, que se refiere a la inclusión de la enseñanza de Historia de África, de las cuestiones raciales y de la cultura afro-brasileña, ampliamente demonizada, en la parrilla curricular. Pensando en cambios decidí crear talleres itinerantes en las escuelas para abordar todo proceso histórico de borrado y demonización de las religiones afrobrasileñas en la historia de Brasil. Contribuyendo así a una educación en la que el racismo y todas las formas de opresión sean descontruidos en la lucha por la igualdad.

Palabras clave: Racismo; La Religión; Educación.

Nos três dias de realização do "Seminário Raça Negra e Educação 30 anos depois: E agora do que mais precisamos falar?" pude ouvir, assim de pertinho, mulheres negras e homens negros que inspiraram toda minha trajetória acadêmica e de militância. Compartilhar esses dias com Petronilha Beatriz Gonçalves e Silva, Anna Maria Canavarro Benite, Carlos Benedito Rodrigues da Silva, Helio Santos, Rachel de Oliveira, Zélia Amador de Deus, Ivair Augusto Alves dos Santos, Nilma Lino Gomes, Sidnei Barreto Nogueira, dentre tantos outros e tantas outras referências negras, foi uma grande honra para mim. Espero carregar esse bastão da luta antirracista com a capacidade e coragem dos que me antecederam e continuar passando essa missão para gerações futuras. Estou bastante nervosa diante da responsabilidade que carrego aqui: pensar sobre avanços, problemas e esperanças desses 30 anos do debate sobre Raça e Educação no Brasil.

Esses 30 anos de história dos quais falamos aqui nesses dias representam também meus quase 30 anos de trajetória de vida. Por isso, pensando em uma perspectiva de oralitura, ou mesmo escrevivência, citando Conceição Evaristo, programei este texto a partir das minhas próprias histórias, tão diferentes e ao mesmo tempo tão parecidas com as histórias de muitos homens negros e muitas mulheres negras nesse país. Longe de pretender ser egocêntrica, apenas coloco meu coração aqui, por sinal, bastante emocionado por tudo que esse momento representa. Havia escrito muitas coisas para apresentar, com vocábulo erudito, dados bem escolhidos, prescritos dentro das normas da 
ABNT e embasados em muitos autores importantes para academia, mas, desde que botei meus pés neste teatro, só consigo pensar na história da minha vida.

Meu nome é Carolina Rocha Silva, filha de Alfredo Fernando da Silva, ambulante, com pouquíssima experiência na escola formal, mas muita inteligência e perspicácia adquirida na vida. Fugiu de casa por causa da violência doméstica praticada por seu pai. Morou na rua, passou muita fome, foi para orfanatos, ganhou um par de sapatos já adulto, foi engraxate, ambulante, serviu a Pátria no militarismo como uma alternativa para fugir da pobreza e, finalmente, frequentou a escola. Fugiu da escola, saiu do exército. Não se enquadrou nem em um e nem em outro. Na verdade, dizia que, no pós-abolição, como não era possível matar, a princípio, a todos os negros e negras do Brasil restava domesticar seus corpos nessas e em tantas outras instituições. Sempre foi nego rebelde, fujão e arisco, com muito orgulho. Depois de carregar muito caixote de feira nos ombros, e encontrar muita gente para ajudá-lo nesse processo, tornou-se feirante, comerciante e administrador de muitas feiras no Rio de Janeiro. Meu pai tinha uma grande paixão: o samba. Foi faxineiro, servente, chefe de harmonia, fundador da Velha Guarda e depois, finalmente, Presidente, da escola de samba que ajudou a construir: a União da Ilha do Governador. Dentro da sua escola de coração foi também chamado de macaco, nego imundo, preto merda, muitas vezes...

Estamos falando de um negro vencedor, muitos diriam, inclusive ele, obedecendo à lógica da excepcionalidade, da qual, me parece, eu também não escapei. Diriam outros que foi a meritocracia a grande responsável pela ascensão social do preto, que trabalhou duro e chegou lá. Lá onde? Lá onde o racismo também está, perverso e aniquilante. Alfredo militou em muitas frentes antirracistas, ajudou muita gente e contribuiu para um mundo menos injusto, acho eu. Também não foi um pai presente, nem para mim e nem para os meus sete irmãos, mas morria de orgulho de nós e sempre enfatizou o quanto a educação era importante, sem, contudo, deixar de nos lembrar que o racismo faria de tudo para nos afastar da escola e que ela não era a única forma de vencer na vida.

Outro dia, estava almoçando com minha irmã mais velha, Thatiany, e resgatando algumas memórias da infância nas quais nosso pai estava presente. Ela lembrou quando sofreu racismo na escola e ele foi no colégio tirar satisfação sobre o caso. Chegando lá, disse para a diretora, que não "conseguia" enxergar atitudes racistas em sua escola, o seguinte: "onde a senhora nunca vai pôr o dedo, eu sento a bunda". Rimos por muito 
tempo e louvamos essa "bunda" ousada, que ocupou muitos espaços, destinados a uma elite branca e rica. Dentre os meus irmãos, fui a primeira a ter um diploma de graduação, e não me orgulho disso. Hoje, me orgulho de dizer que mais uma irmã fez faculdade. Faculdade privada, porque a universidade pública ainda é muito restrita aos pretos e pretas deste país.

Minha mãe, Maria Eugenia da Fonseca Rocha, começou a trabalhar aos 14 anos. Ao longo da vida foi datilógrafa, secretária, balconista, vendedora, ambulante e empregada doméstica. Nunca fez faculdade, porque a prioridade era trabalhar para sustentar a casa e ajudar a criar as irmãs, mas sempre me dizia que seu sonho era me ver formada, doutora: "minha filha, você é preta e pobre, portanto, precisa ser a MELHOR". Ela trabalhou duro, em dois e até três empregos de uma vez, para me fazer ser a melhor.

Contei a história dos meus pais, hoje meus ancestrais, porque tem tudo a ver com a futura doutora que sou hoje. Saudei, no início, as minhas mais velhas e os meus mais velhos, que lutaram contra o mito da democracia racial, contra o genocídio do povo preto, contra toda violência que incide sobre as mulheres negras, e que conquistaram as cotas e a lei n. 10.639, porque sem eles eu não estaria aqui.

Estudei até o fim do primário em escola pública municipal e depois fui para o Colégio Pedro II, fiz prova e entrei na "recla", da "recla", da reclassificação. Na época, a gente tinha o grêmio e as lutas pelo passe livre, mas nenhum coletivo preto ou feminista na instituição, como hoje. Fiz parte dessas lutas, mas não via todas as minhas questões, enquanto mulher negra, representada nelas. Eu era então, apenas a Carol Macaca da escola, chamada assim mesmo pelos amigos mais queridos. Nessa época, um professor de história negro, Célio Generoso, foi quem me incentivou a fazer vestibular. Entrei na Universidade Estadual do Rio de Janeiro (UERJ), em 2005. O cenário era de uma turma noturna de serviço social, majoritariamente preta e cotista, na qual vi muitos colegas desmaiando de fome, depois de um dia intenso de trabalho. Havia muita solidariedade e ajuda entre nós e também muitas pautas em disputa, nos questionávamos, por exemplo, sobre como manter os alunos cotistas na universidade e pedíamos a bolsa permanência, ameaçada hoje pelo governo do estado.

Saí da UERJ e fui para a Universidade Federal Fluminense (UFF) cursar história, meu grande sonho. Descortinava à minha frente, a partir de então, outro contexto: curso diurno, pouquíssimos pretos e pretas. Depois veio o mestrado, nenhum preto ou preta no 
corpo discente, nenhum professor preto ou professora preta. Adoeci no mestrado e depois veio trabalho e mais trabalho. Até que finalmente o doutorado, de novo na UERJ. Em 2017, no Instituto de Estudos Sociais e Políticos da UERJ, o IESP, fundamos um coletivo de alunas pretas e alunos pretos, infelizmente com quórum reduzido, mas muita coragem e vontade de ver mudar a cor da pós-graduação neste país. Criamos, aos moldes do que foi feito pelo coletivo de pretas e pretos do Museu Nacional, um curso preparatório para o ingresso no mestrado de alunas negras e alunos negros. Lembro-me do primeiro dia de aula, turma cheia, preta, trabalhadora, e com idades mais avançadas do que se costuma ver na universidade. Desses, três alunos/alunas passaram na prova, o que para nós foi uma grande vitória.

Hoje faço parte da Comissão da Diversidade de Gênero no Colégio Pedro II, que agrega vários coletivos de alunas negras e alunos negros, vou às reuniões para ouvir e aprender com eles. O quanto têm nos ensinado os coletivos autogestionados nas escolas? O que significou ver escolas de todo Brasil ocupadas por alunos e alunas em busca de melhores condições e menos opressões? Estamos aprendendo muito com essa nova geração que nos indaga: a escola é de quem mesmo? Pensando em tudo isso, comecei em 2015, enquanto doutoranda, a dar oficinas em escolas públicas para falar de racismo religioso e intolerância religiosa. Porque não acredito em uma universidade que não é capaz de dialogar e fazer sentido na educação básica. Existe uma hierarquia verticalizada, trazida, inclusive, no nome do tal "ensino superior", que nos distancia e desagrega. Assim, em dúvida, o movimento negro, os tantos movimentos de reivindicação que têm se mobilizado pelo país, o Candomblé e minha família, para além da escola formal, foram os grandes educadores da minha vida. O cenário atual é de muita opressão e desânimo, mas a resposta a esses tempos difíceis tem se mostrado, igualmente, potente. A Marcha das Mulheres Negras neste ano, em Copacabana, foi um desses momentos lindos e fortalecedores das nossas lutas.

Infelizmente, a realidade educacional brasileira continua confirmando o caráter estrutural da desigualdade racial no país. Segundo os dados estatísticos do Censo de 2010, existem 14 milhões de brasileiros com mais de 15 anos que são analfabetos, destes $30 \%$ são brancos e 70\% são pretos ou pardos. De acordo com os dados do IBGE (2010), 31,1\% dos brancos entre 15 e 24 anos terminaram o ensino superior, enquanto apenas $12,8 \%$ dos pretos e $13,4 \%$ dos pardos têm o mesmo nível de instrução. 
A maioria de nós, alunos negros e alunas negras, estão na escola pública, que, além de enfrentar dificuldades referentes a recursos e infraestrutura, costuma ser despreparada para lidar com o racismo e com a implementação da Lei federal $n$. 10.639/03, atualizada na lei n. 11645/08, que se refere à inclusão do ensino de História da África, das questões raciais e da cultura afro-brasileira na grade curricular. A aplicação da lei é de suma importância para recuperar em sala de aula tensões raciais silenciadas, recuperar a autoestima e a história de nosso povo e repensar o papel da negra e do negro no Brasil como sujeito protagonista na construção social.

Comecei a desenvolver oficinas itinerantes para falar de racismo religioso nas escolas públicas do Rio de Janeiro em 2015, cujo objetivo era dialogar com discentes e docentes sobre todo o processo histórico de apagamento e demonização das religiões afrobrasileiras na história do Brasil. No entanto, fui impedida de realizar esse trabalho em muitas escolas sob alegação de estar a serviço do demônio. Eu mesma, uma mulher candomblecista, fui chamada de agente do diabo. Diretoras e professoras a serviço de sua religião cristã, genericamente identificadas como evangélicas, impedem ou dificultam que se rompa com os estereótipos negativos ligados às religiões afro-brasileiras, sob alegação de que, ao cumprir a lei, estar-se-ia doutrinando ou convertendo alunos. A despeito disso, os livros didáticos contemplam os deuses europeus pré-cristãos e toda a história do Cristianismo, que são apenas uma parte da formação cultural brasileira.

O que se convencionou, mais recentemente, chamar de intolerância religiosa no Brasil foi constitutiva do processo de colonização do país, deixando suas marcas no âmbito cultural e político-estatal até os dias atuais. Assim, observamos a presença constante da intolerância religiosa em nossa história, com mudanças que dizem respeito aos atores que a perpetraram/perpetram (ora colonizadores, ora agentes do estado, ora líderes religiosos) e aos argumentos que baseavam/baseiam suas ações (Cunha, 2012, p. 96).

Assim, episódios violentos ligados à destruição de terreiros e ofensas a símbolos religiosos afro-brasileiros são documentados desde o final do século XIX no Brasil. O código penal de 1890, por exemplo, criava mecanismos legais para combater os chamados "feiticeiros" (Maggie, 1992). As religiões afro-brasileiras, cercadas pela intolerância e pelo preconceito, foram alvo da Igreja católica e do Estado, que procurou estigmatizar seus ritos e símbolos ligando-os à criminalidade e ao diabo. 
O diabo cristão era considerado o agente universal de todo mal sobre o mundo. E, mais que isso, ele era visto como o principal aliado de todos os opositores, efetivos ou imaginários, da Igreja cristã. A visão de mundo dualista do Cristianismo tornou herético e diabólico todo sagrado não oficial. Nesse contexto, o diabo, que percorreu um longo caminho no imaginário europeu antes da colonização do Brasil, foi integrado à religiosidade de escravos africanos e dos indígenas. Para garantir o êxito do projeto colonizador do homem branco europeu, os africanos foram inferiorizados, demonizados e escravizados por séculos. As consequências desse processo são alarmantes no Brasil até os dias de hoje, quando testemunhamos o racismo e a demonização da cultura de matriz africana, com violentos casos de intolerância religiosa.

A Igreja católica e o Estado sempre tiveram uma relação simbiótica no Brasil. No período colonial era expressamente proibido professar outra religião que não fosse a da Igreja Católica Apostólica Romana. Durante o Império, o catolicismo continuou a vigorar como a religião oficial no país. O artigo 176 do código criminal de 1830, por exemplo, punia a celebração, a propaganda e o culto de outras religiões. Só a primeira Constituição da República, em 1891, torna o Estado laico e prevê a separação entre religião e poder político. A partir daí a liberdade religiosa passou a ser defendida por lei, o que não impediu a perseguição das religiões afro-brasileiras durante todo o século XX até os dias de hoje. Suas práticas foram historicamente demonizadas e criminalizadas, principalmente se estavam ligadas a terreiros de áreas pobres e negras (Cunha, 2012).

Aos poucos, na sociedade contemporânea, o debate acerca da religião verdadeira foi banido da esfera pública e relegado ao foro íntimo e privado. As questões teológicas perderam impacto na vida pública e o direito fundamental à liberdade religiosa foi a resposta política apropriada aos desafios do pluralismo religioso na modernidade. No entanto, mesmo após a laicização do Estado, no qual a religião deixou de ser um fator de unidade política, o catolicismo permaneceu como religião hegemônica e influente no Brasil, enquanto que o imaginário social e policial criminalizava as expressões religiosas afro-brasileiras presentes na religiosidade popular.

A partir de meados de 2006, o debate religioso voltou a ser protagonista das discussões políticas atuais, principalmente pelo comportamento e discurso extremista de algumas Igrejas, de denominação neopentecostal. A recente "conversão" de traficantes 
de drogas ao neopentecostalismo e a expulsão de pais de santo das favelas e periferias do país, notadamente no Rio de Janeiro, reacendeu as polêmicas sobre um velho problema que vem se arrastando por toda a história do Brasil:

Os instrumentos acessados pelos neopentecostais para a dinâmica do conflito estão presentes no mundo evangélico, mas não só. Estão presentes na cultura e não foram inventados por evangélicos. Trata-se de uma herança colonial, derivada da dominação de Estado feita pelo catolicismo. As formas de dominação latino-ibéricas, ao contrário das colonizações anglo-saxãs, não negaram nem os deuses nem a religiosidade dos colonizados, a lógica sempre foi a da apresentação de um deus maior e vitorioso sobre todas as religiosidades e entidades que habitam a colônia. Enfim: nada de novo em relação ao modo de guerra que estabelecem os neopentecostais. [...] na mesma cultura nasceu e sobrevive o racismo e o preconceito, instrumentos sociais de segregação de toda a sorte, especialmente da contínua redução das religiosidades dos negros $[\ldots]^{2}$.

O pentecostalismo teve crescimento mundial a partir da década de 1960, principalmente dentro dos contextos de maior precariedade político-social. A missão pentecostal manteve seu foco nas pastorais destinadas ao meio urbano, considerado fonte de intensas "Batalhas Espirituais" entre o bem e o mal, entre Deus e o Diabo. Na perspectiva teológica e doutrinária dos evangélicos pentecostais, o mundo é um local de guerra, e o linguajar bélico empregado pelos pastores, que falavam o tempo todo do "inimigo" a ser combatido e do "exército do senhor" a ser convocado, comunicou bem com os moradores das favelas e periferias pobres, notadamente os bandidos. Além disso, a proximidade e a vida similar entre pastores e moradores das favelas gerou uma empatia maior com relação ao culto, diferente do que acontecia com os padres da Igreja Católica, por exemplo, que residiam em áreas distantes. O acesso facilitado ao culto e a ampla oferta de igrejas (observa-se a facilidade de fundar templos em decorrência de cisões religiosas frequentes), que cresceram de maneira menos verticalizada e hierarquizada que o catolicismo oficial, também foram fatores que contribuíram para a evangelização de um número cada vez maior de fiéis.

Outro aspecto importante que contribuía para popularizar o culto era o grande acolhimento promovido pelas igrejas, os “irmãos" geravam uma rede de solidariedade e proteção que envolvia de afeto e confiança o membro novo, geralmente acostumado com um ambiente inseguro, hostil e vulnerável. As igrejas eram formadas por circuitos de

\footnotetext{
2 Rafael Oliveira Soares em entrevista para Marcela Belchior em 30/05/2015, disponível em: http://www.redebrasilatual.com.br/cidadania/2015/05/no-brasil-intolerancia-religiosa-nega-culturamestica-4514.html. Acesso em: 15 de julho de 2017.
} 
reciprocidade que favoreciam as relações materiais entre seus membros, com o incentivo à ajuda mútua e aos impulsos empreendedores. $\mathrm{O}$ fiel era enraizado na igreja, vivida por ele como totalidade social, espiritual e familiar (Cunha, 2009 b, p. 234-235).

A conversão possibilitava ainda para o morador da favela o respaldo moral e ético dentro de um contexto que envolvia pobreza, violência e criminalidade: "por manterem uma postura segregadora em relação ao 'mundo secular`e às 'coisas do mal é que os pentecostais conseguem uma posição de respeito" (Teixeira, 2006, p. 51). Aos poucos, as mães de santo locais, enfraquecidas social e politicamente, iam perdendo espaço para os evangélicos "guardiões da moral" e propagadores da "verdade".

O crescimento neopentecostal, a partir dos anos 1970/1980, centralizava ainda mais o discurso teológico anterior no modelo da "Batalha Espiritual", investindo no proselitismo religioso justificado por uma necessidade de cura, promovendo uma convocação nacional da libertação, principalmente por meio da mídia televisiva, e aproveitando-se do apelo mágico exigido pelos fiéis. No meio de todo esse contexto, assiste-se à criação de um dos maiores símbolos do crescimento neopentecostal no Brasil: a Igreja Universal do Reino de Deus. Insuflados pela crença na teologia da "cruzada espiritual”, os fiéis lutavam contra os demônios das religiões afro-brasileiras, seu principal alvo (graças à eficácia reduzida dos ataques aos símbolos do catolicismo, religião ainda majoritária e hegemônica) (Pereira, 2013, p. 220-221).

O neopentecostalismo, diferente do que foi o pentecostalismo clássico ascético das décadas anteriores, se aproximava e se apropriava do sistema simbólico de manipulação mágica da umbanda e do candomblé para depois negá-lo e demonizá-lo. O elemento principal de inversão e mediação desse discurso esteve concentrado em protagonistas específicos, os Exus, tidos como diabos que proliferavam o mal pelo mundo (Pereira, 2013, p. 226). Assim, os altares dos templos neopentecostais viravam grandes palcos de exorcismos de pessoas incorporadas por Exus $^{3}$ que desejavam disseminar o ódio e a guerra de acordo com a sua perspectiva.

\footnotetext{
${ }^{3}$ Os Exus cultuados na umbanda são espíritos que viveram no mundo carnal dos homens e, após a morte, passaram a incorporar seus espíritos em médiuns na forma de exus (entidade masculina) e pombagiras (entidade feminina) para fazer trabalhos espirituais de caridade e evoluir espiritualmente. Por ainda estarem em processo evolutivo são apegados à vida terrena e, em alguns casos, podem beber e fumar. Seu caráter
} 
Cerca de mil casos de intolerância religiosa foram registrados pelo Centro de Promoção da Liberdade Religiosa e Direitos Humanos (Ceplir) no Rio de Janeiro em dois anos e meio. Desses, mais de 900 queixas datam de julho de 2012 a dezembro de 2014. E a maioria esmagadora das denúncias identificadas como crimes de intolerância religiosa atingem negros, membros das religiões afro-brasileiras, vítimas, principalmente, de religiosos neopentecostais. Esses dados estão em um relatório preliminar divulgado no dia 18 de agosto de 2015 pela CCIR [Comissão de Combate a Intolerância Religiosa], em audiência pública na Assembleia Legislativa do Estado (Alerj) ${ }^{4}$.

Em junho de 2015, a menina Kayllane Campos, de apenas onze anos, foi apedrejada após sair de uma cerimônia de candomblé na Vila da Penha, Zona Norte do Rio de Janeiro. Como ainda não foi implementada uma delegacia especializada em intolerância religiosa, o caso foi registrado no artigo 20 da Lei n. 7.716/89 - Lei Caó (que define os crimes resultantes de preconceito de raça ou de cor) punitiva de crime racial e intolerância. O despreparo e a desinformação dos agentes de segurança dificultam a identificação dos crimes de intolerância religiosa, muitas vezes diagnosticados como injúria racial ou até tratados pejorativamente como "brigas de vizinhança", e, consequentemente, a elaboração de índices estatísticos, utilizados para pleitear ações governamentais e demonstrar a urgência desses casos. $\mathrm{O}$ caso de Kayllane gerou grande repercussão, inclusive internacional, e tem fomentado ainda mais o debate e a luta por políticas públicas no plano municipal para garantir os direitos civis da população afro-brasileira. Muitas entidades promotoras da liberdade religiosa defendem que o município deve elaborar, obrigatoriamente, documentos e cartilhas para pautar temas como o racismo e a intolerância religiosa, assim como, as propagandas do Governo Federal e do Estado na televisão.

O mito da mestiçagem, que outrora camuflou o racismo no Brasil, assim como o mito da paz religiosa que, pouco a pouco, desmorona, procurou esconder a desigualdade de oportunidades de direitos que acompanha a história do país. Práticas racistas e segregadoras, mesmo que não sejam oficiais ou definidas por lei, continuam a ser perpetuadas, condenando uma parcela significativa da população à estereotipização e à

não é plenamente definido, portanto devem ser doutrinados pelos pais de santo para fazerem a prática do bem.

4 “Quase mil casos de intolerância religiosa foram registrados no Rio em dois anos”. Disponível em: EBC Agência Brasil em 18/08/2015. 
marginalização. A imunidade fiscal, por exemplo, é garantida para as igrejas católicas e assiste alguns templos evangélicos, em contrapartida, na maioria dos municípios, cobrase o Imposto Predial e Territorial Urbano (IPTU) para casas de umbanda e candomblé. Somado a isso, há empecilhos no atendimento hospitalar, que muitas vezes não respeitam as restrições alimentares dos filhos de santo, nos rituais funerários e nas escolas, muitas vezes excludentes com seus códigos culturais.

Outro caso de racismo religioso bastante noticiado pela mídia ocorreu em 2014, quando um menino de doze anos foi barrado numa escola municipal da Zona Norte do Rio de Janeiro por usar bermudas brancas e fios de conta próprios das religiões afrobrasileiras por baixo da camisa. A mãe do aluno avisou previamente a professora que o aluno estaria cumprindo uma prescrição da sua religião, o Candomblé, mas ele foi proibido de entrar no colégio. A função do ensino público e gratuito no país é justamente permitir acesso a todos, independentemente de cor, religião e/ou renda. Sua responsabilidade é muito grande, como um local de construção da cidadania. Entretanto, o fato de haver mais de $50 \%$ de alunos negros na rede pública não indica inclusão ${ }^{5}$, existem outras questões em pauta como o aproveitamento da vida escolar por essas crianças e adolescentes negros e, principalmente a forma como é abordada a história e os dilemas enfrentados pela cultura afro-brasileira em sala de aula.

Falta investimento na escola pública, não só para universalizar seu acesso, como para melhorar a qualidade da educação no país. A maior parte dos alunos negros não chega a concluir seus estudos, no ensino médio o número de matriculados despenca. Se ser pobre no país é um problema, ser pobre e negro parece ser um problema maior ainda, isso porque, além do problema de desigualdade social, enfrenta-se o da discriminação racial. O problema é que "criou-se uma verdadeira ética do silêncio em relação à cor dos brasileiros" 6 . Vivemos o mito da igualdade racial usando como desculpa a mestiçagem, e o brasileiro chega a sentir-se desconfortável ao falar em raça/cor. Daí a importância dos debates em torno do tema, recuperando tensões silenciadas que ajudam a enfrentar a realidade. Nos últimos anos, aumentaram as discussões sobre ações afirmativas e direitos

\footnotetext{
${ }^{5}$ O Censo Escolar de 2005, feito pelo Inep (Instituto Nacional de Estudos e Pesquisas Educacionais), foi o primeiro a levantar dados sobre a etnia dos estudantes. Constatou-se que apenas um terço dos alunos matriculados no ensino fundamental e médio de escolas particulares, que declaram a etnia, se considera negro, preto ou pardo. Nas escolas públicas o índice ultrapassa $56,4 \%$ dos estudantes.

${ }^{6}$ Mattos, Hebe. "Das Cores do Silêncio". Jornal $O$ Globo, p. 7, 06/07/2006.
} 
de reparação para as populações afrodescendentes. Cada vez mais é urgente a necessidade de implementar medidas que promovam, de fato, a igualdade social garantida pela Constituição, valorizando a pluralidade étnica e cultural brasileira.

Entre brancos, negros, mestiços, amarelos, índios, pobres e ricos, o professor não pode esquecer seu papel social. O ensino é um instrumento de luta e transformação social, desperta nos alunos uma consciência crítica que lhes permite superar o senso comum e enxergar os acontecimentos de forma reflexiva. Que a educação ajude a construir uma sociedade melhor para todos, mais justa e menos marcada por tensões raciais. No entanto, é difícil cobrar esse importante papel dos professores se eles mesmos estão mal preparados e pouco estimulados. Muitas escolas não se adequaram à lei n. 10.639 e se queixam principalmente do despreparo dos professores em relação ao tema, do pouco material didático produzido sobre a história e cultura afro-brasileiras, somado ao preconceito de certas instituições, principalmente, em relação à religião. Alguns alunos e pais de alunos acusam os professores de promover a adoração do diabo, que para eles é o grande interlocutor das religiões e de vários aspectos da cultura afro-brasileira. Assim, mais uma vez, a cultura afro é criminalizada e demonizada por um Estado predominantemente cristão.

A educação e a informação são os grandes aliados na luta contra a intolerância e o racismo. A Lei n. 10639 cumpre um papel fundamental nessa luta e precisa ser valorizada. A própria lei Caó, criada há mais de 25 anos contra crimes raciais, de etnia e de religião, não é efetivada. Anseia-se pela criação de uma delegacia especializada e de informação sobre a cultura e os cultos afro-brasileiros, porque os crimes de intolerância religiosa estão relacionados a muitos outros crimes, ligados ao racismo, ao machismo e à homofobia. Não é só uma religião que está sendo desrespeitada e agredida, mas toda uma cultura, silenciada como parte da formação cultural do povo brasileiro.

Ainda que o duro golpe da pretensão de uma escola sem partido nos assole, precisamos continuar a luta para que alunas negras e alunos negros tenham representatividade na história do Brasil, para além de uma população escrava homogênea, passiva e submissa. Dessa forma, precisamos pensar em formas outras de pedagogias que atendam de forma melhor a realidade dos nossos alunos de favela e periferia no Brasil, majoritariamente negras e negros. Azoilda Loretto da Trindade, importante professora e 
ativista negra brasileira, ao enfatizar a importância do uso dos "valores civilizatórios afrobrasileiros" para a educação infantil traz novas perspectivas sobre os saberes africanos, constantemente silenciados, que herdamos: "Valores inscritos na nossa memória, no nosso modo de ser, na nossa música, na nossa literatura, na nossa ciência, arquitetura, gastronomia, religião, na nossa pele, no nosso coração" (2013, p.30). Assim, destaca princípios como energia vital, oralidade, circularidade, corporeidade, musicalidade, ludicidade e cooperatividade. Trazer essas narrativas e memórias, e compartilhar com outros educadores traz alternativas para superar o racismo, e colabora com o projeto que luta por uma educação inclusiva e crítica, na qual o racismo, o sexismo, a homofobia, os conflitos e os preconceitos de classe não fiquem esvaziados em um discurso de universalismo cego às diferenças, mas, sim, sejam objetos a se desconstruir em uma luta por igualdade.

\section{REFERÊNCIAS}

CUNHA, Christina Vital da. Conflitos religiosos e a construção do respeito à diversidade: breve histórico e iniciativas recentes. In: LIBONATI, André; GARCIA, Débora; EITLER, Kitta. (Org.). Comunicação e Transformação Social 2 - Canal Futura 15 anos na estrada. São Leopoldo: Editora Unisinos, 2012. p. 98.

. Evangélicos em ação nas favelas cariocas: um estudo sócio-antropológico sobre redes de proteção, tráfico de drogas e religião no complexo de Acari. Tese (Doutorado em Ciências Sociais) -Universidade Estadual do Rio de Janeiro, Rio de Janeiro, 2009a.

Da macumba às campanhas de cura e libertação: a fé dos traficantes de drogas em favelas no Rio de Janeiro. Tomo - Revista do Programa de Pós-Graduação em Sociologia, São Cristóvão, n. 14, p. 229-265, jan/jun., 2009b.

INSTITUTO BRASILEIRO DE GEOGRAFIA E ESTATÍSTICA (IBGE). Censo Brasileiro de 2010. Rio de Janeiro: IBGE, 2012.

MAGGIE, Yvonne. Medo de feitiço: relações entre magia e poder no Brasil. Rio de Janeiro: Arquivo Nacional, 1992.

PEREIRA, Vitor Pimentel. Mentalidade iconoclasta e Direito á Liberdade Religiosa na Sociedade Plural: o caso da destruição de centros espíritas no Rio de Janeiro. Revista de Direito da Cidade, Rio de Janeiro, v. 5, n. 1, p. 351-373, 2013.

SILVA, Vagner Gonçalves da (org.). Intolerância religiosa: impactos do neopentecostalismo no campo religioso afro-brasileiro. São Paulo: Editora da Universidade de São Paulo, 2007.

TEIXEIRA, Cesar Pinheiro. O Pentecostalismo em contextos de violência: reflexões sobre religiosidade popular. Monografia em Ciências Sociais. UERJ/IFCH, Rio de Janeiro, 2006. 
TRINDADE, Azoilda Loretto da. Valores civilizatórios afro-brasileiros na educação infantil. In: TRINDADE, Azoilda Loretto da (org.). Valores Afro-brasileiros na Educação. Salto para o futuro. Rio de janeiro: TV escola /MEC, 2013. Disponível em: http://www.diversidadeducainfantil.org.br/PDF/Valores\%20civilizat\%C3\%B3rios\%20afrobrasil eiros\%20na\%20educa\%C3\%A7\%C3\%A3o\%20infantil\%20-\%20Azoilda\%20Trindade.pdf. Acesso em 30 de setembro de 2016. 